\title{
Road traffic crashes in Ramadan: an observational study
}

M.N. Tahir, ${ }^{1}$ G. Macassa, ${ }^{2}$ A.H. Akbar, ${ }^{3}$ R. Naseer, ${ }^{1}$ A. Zia ${ }^{7}$ and S. Khan ${ }^{1}$

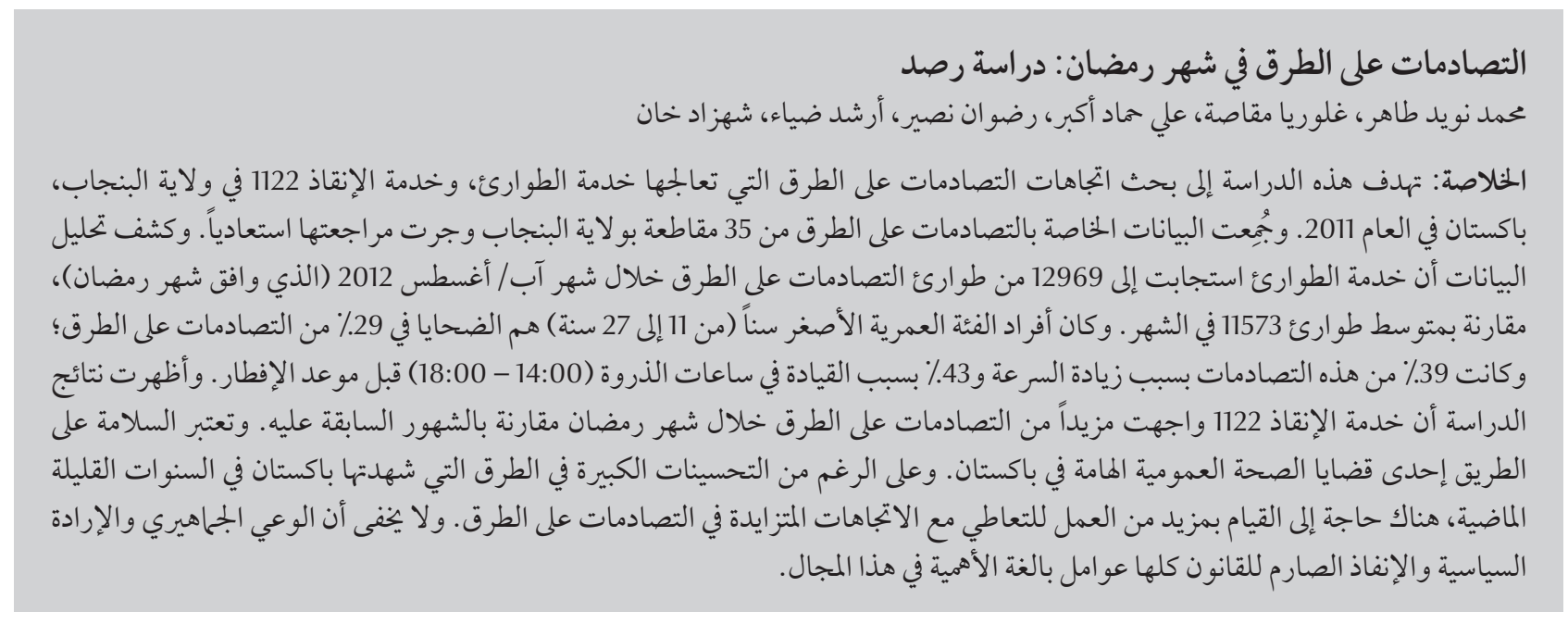

ABSTRACT The aim of this study was to investigate trends in road traffic crashes (RTCs) managed by an emergency service, Rescue 1122, in 2011 in Punjab, Pakistan. RTC data were collected from 35 districts of Punjab and reviewed retrospectively. Data analysis revealed that the service responded to 12969 RTC emergencies during August 2011 (Ramadan), compared with an average of 11573 RTCs per month from January to August 2011. The younger age group (11-27 years) was victims in 29\% of RTCs; $39 \%$ were due to speeding and $43 \%$ occurred in peak rush hours (14:00-18:00) before iftar (breakfast).Results of the study showed that Rescue 1122 faced more RTCs during Ramadan compared with the preceding months. Road safety is an important public health issue in Pakistan. Although there have been great improvements in roads in the past few years, much work needs to be done to deal with mounting trends in RTCs. Public awareness, political will and stringent law enforcement are key factors.

\section{Accidents de la circulation pendant le Ramadan : étude d'observation}

RÉSUMÉ L'objectif de la présente étude était de connaître les tendances en matière d'accidents de la circulation pris en charge par le service d'urgence «Rescue $1122 »$ au Pendjab (Pakistan) en 2011. Les données sur ces accidents ont été recueillies dans 35 districts du Pendjab et examinées rétrospectivement. L'analyse des données a révélé que le service était intervenu dans 12969 urgences routières pendant le mois d'août 2011 (Ramadan), par rapport à une moyenne mensuelle de 11573 urgences routières entre janvier et août 2011. Le groupe d'âge le plus jeune (11-27 ans) représentait $29 \%$ des victimes d'accidents de la circulation ; $39 \%$ étaient dus à la vitesse et $43 \%$ ont eu lieu pendant les heures de pointe de la circulation (entre 14 et 18 heures) avant la rupture du jeûne (iftar). Les résultats de l'étude ont souligné que le service d'urgence « Rescue 1122 » a dû prendre en charge un plus grand nombre d'accidents de la circulation pendant le Ramadan que pendant les mois précédents. La sécurité routière est une question de santé publique importante au Pakistan. Si des améliorations majeures ont été observées sur les routes ces dernières années, il reste beaucoup à faire pour s'attaquer à l'augmentation croissante des accidents de la circulation. Les facteurs clés sont la sensibilisation du public, une volonté politique et une stricte application de la loi. 


\section{Introduction}

Road traffic crashes (RTCs) are one of the most pressing international health and development concerns in the world. Every year, nearly 1.3 million people die as a result of a road traffic collision more than 3000 deaths each day - and more than half of these people are not travelling in a car $[1,2]$.

In Pakistan, half of all major incidents and two thirds of all deaths in major incidents are due to RTCs [3]. Two independent population-based surveys estimated the incidence of road traffic injuries to be around $15-17$ per 1000 persons per year in Pakistan [4-6].

It is estimated that approximately 40000 people die on the roads every year in Pakistan and many more sustain serious injuries [6]. In addition to the suffering, these injuries contribute significantly to the workload in hospitals, leading to direct costs to the Pakistani economy of over US\$ 1 billion $[4,7,8]$.

Various studies in many countries have raised the issue of the increased number of RTCs during holidays and festive periods such as Christmas and New Year [9-11]. In the United States of America for instance, the numbers of motor vehicle fatalities were usually higher in six holiday periods: New Year, Memorial Day, 4th of July, Labour Day, Thanksgiving and Christmas. Between 1978 and 2002, the three deadliest days for pedestrians were 1 January, 23 December and 31 October (Hallowe'en) [12-14].

In countries that celebrate Ramadan, Eid al-Fitr and Eid al-Adha, an increasing trend of RTCs has also been documented [15-18]. Ramadan is the ninth month of the Islamic calendar and lasts 29 or 30 days. It is the Islamic month of fasting, in which participating Muslims refrain from eating, drinking, smoking and sex during daylight hours. It is intended to teach Muslims about patience, spirituality, humility and submissiveness to God. The dates of Ramadan vary, moving backwards by about 11 days each year depending on the moon. In 2011, Ramadan was celebrated between 1 August and 30 August [19].

This study aims to investigate the trends of RTCs that were managed by a rescue service, Rescue 1122 in 2011 in Punjab, Pakistan.

\section{Methods}

\section{Study setting}

The study was conducted at the Lahore headquarters of Rescue 1122. Rescue 1122 is an emergency service that offers ambulance, fire, emergency response teams, water rescue and safer community programme to over 80 million people in the Punjab $[20,21]$. The Punjab is the largest province of Pakistan, with 36 districts. Rescue 1122 is operational in all 36 districts. The service operates in urban settings and works through a toll-free number 1122. It is state funded and operates over 24 hours, 7 days a week $[20,21]$.

\section{Study design}

In this retrospective study, RTC data for the period January-August 2011 were retrieved and examined. The data were collected by the emergency medical technicians from the scene of the crash. The emergency medical technicians are the first responders of the Rescue 1122 ambulance service. They fill out an emergency response form at the scene of the RTC and during the journey to hospital. The emergency response form includes basic first-hand information regarding the crash (e.g. demographics of victims, type and cause of crash, vehicles involved).

The data included all RTCs reported to the service during the study period from 35 districts of Punjab. Final data analysis was carried out using statistical software SPSS version 16.

\section{Results}

Rescue 1122 attended 92587 RTC emergencies during the 8 months (January-August 2011) of the study period. The breakdown of monthly RTCs data shows that the service responded to 10334 RTCs calls in January, 10351 in February, 11957 in March, 11394 in April, 11885 in May, 11708 in June, 11989 in July and 12969 in August (the Islamic month of Ramadan) (Figure 1).

\section{No. of RTCs}

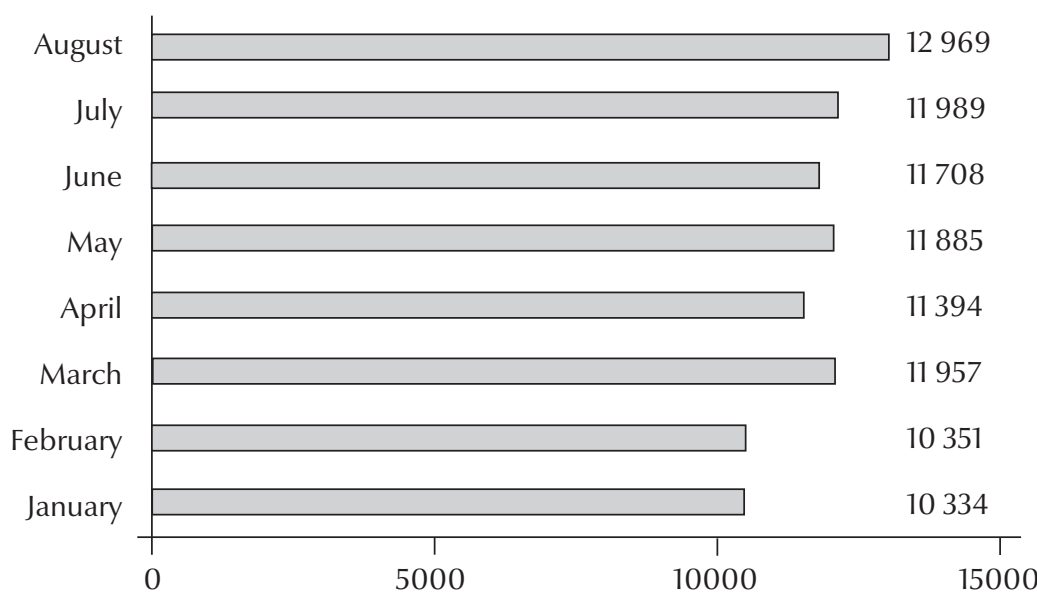

Figure 1 Road traffic crashes (RTCs) managed by Rescue 1122 from January to August 2011 
Detailed analysis of Ramadan 2011 RTCs data showed that the service rescued 14788 victims while responding to 12969 RTC emergencies. The highest number of RTCs were reported in Lahore District (3263), followed by Faisalabad (1205) and Multan (864) (Table 1).

Males were involved in 11633 (79\%) and females in 3155 (21\%) of the total crashes. The younger age group aged 18-27 years were victims in 4325 (29\%), the group aged $28-37$ years in 3038 (21\%) and the group aged 11-17 years in 2565 (17\%) of the total reported RTCs (Table 1).

Motorcycles were the most frequently colliding vehicle, being involved in 9101 (57\%) crashes, followed by cars in 2118 (13\%) crashes. Speeding was found to be the major cause in 4893 (39\%) of RTCs and motorcycling one wheeling was reported in $117(1 \%)$ crashes. The majority of RTCs (5516; $43 \%$ ) occurred between 14:00 and 18:00. Fractured bones (3102; 22\%) and head injuries (1328; 9\%) were the major injury outcomes of the RTCs (Table 1).

\section{Discussion}

RTCs are the major emergency dealt with by the Rescue 1122 ambulance service. The service has attended nearly 6 million RTCs in Punjab in the past 7 years. The results of this study revealed a growing rate of RTCs in 2011. Rescue 1122 faced an increased burden of RTC emergencies in August 2011 (the Islamic month of Ramadan). In this month, the number of RTCs was 1469 higher than the average of 11573 RTCs per month. Speeding was the leading cause of these collisions and the majority of the crashes were reported between 14:00 and 18:00.

These findings could be attributed to the fact that government offices and private businesses usually finish earlier during Ramadan than during the rest
Table 1 Epidemiology of road traffic crashes (RTCs) reported to Rescue 1122 during Ramadan 2011

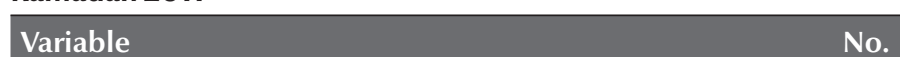

Total no. of reported RTCs

No.

Total no. of victims rescued

12969

14788

Sex

Male

No. $(\%)(n=14788)$

Female

$11633(79)$

$3155(21)$

Age groups (years)

0-10 $703(5)$

$11-17 \quad 2565(17)$

$18-27 \quad 4325(29)$

28-37 $3038(21)$

38-47 2198 (15)

48-57 $1215(8)$

$>58 \quad 744$ (5)

Road user groups/type of vehicle

Motorcycle $9101(57)$

Car 2118 (13)

Rickshaw 1407 (9)

Coach/van 514 (3)

Bus $352(2)$

Truck $366(2)$

Bicycle 340 (2)

Tractor/trolley 223 (1)

Non-motorized vehicle 221 (1)

$\begin{array}{ll}\text { Pedestrians } & 382(2)\end{array}$

Others 958 (6)

Types of injuries sustained

Minor $^{\mathrm{a}}$

8408 (59)

Fractures $3102(22)$

Head $1328(9)$

Neck $64(0.4)$

Spine 119 (1)

\section{Causes of RTC}

Speeding

$4893(38)$

Carelessness

3769 (29)

Wrong turn

$1180(9)$

Bad road conditions 231 (2)

$\begin{array}{ll}\text { Burst tyre } & 160(1)\end{array}$

One wheeling 117 (1)

Collision with structure $\quad 165$ (1)

Faulty vehicle $\quad 166$ (1)

Bad weather conditions 116 (1)

Other causes 2226 (17)

\section{Time of incident}

06:00-10:00 1767 (14)

10:00-14:00 2200 (17)

14:00-18:00 $5516(43)$

18:00-22:00 $2192(17)$

22:00-02:00 $830(6)$

02:00-06:00 464 (4)

a"Minor injury" stands for all those injuries where sustained injuries were not very serious (e.g. small cuts, abrasions and scratches) and these victims were usually discharged from the scene of the crash after first aid. 
of the year, as people wish to be at their homes before iftar (the evening meal when Muslims break their fast). Thus, to return home early, drivers may become impatient and violate traffic rules (e.g. signal violations, speeding, overtaking), often resulting in different forms of RTCs.

Another study [15] conducted in Karachi, which analysed frequency of injuries in Ramadan in 2009 and 2010, confirms this trend. It found that traffic behaviour changed in the approach to iftar and speeding was observed, increasing the chances and severity of crashes [15]. This trend was also witnessed in other countries celebrating Ramadan [16-18].

Another reason for increased traffic and busy roads in Ramadan is the increase in seasonal vendors. These vendors often occupy spaces on the main roads and pedestrian pavements, thus not only obstruct the flow of traffic but also hinder pedestrian mobility. Before iftar, the markets are also packed with people buying traditional foods for Eid.

In the present study, young motorcyclists were predominately involved in the reported RTCs. Fractures of extremities and head injuries were the major injuries sustained by these young people. This is in line with the findings of WHO that young people, especially motorcyclists in low-income and middle-income countries, carry a large proportion of the global burden of road traffic death and serious injury [1-2]. Similar findings have also been reported in research studies from Pakistan [4-8,21-23], India [24-27] and other countries [28-34].

In this study, motorcycling one wheeling also contributed to the RTC toll. This phenomenon has commonly been observed in Pakistan's big cities, especially on weekends, public holidays, Chand Rat (night before Eid) and New Year's night [35-37]. One wheeling on 14 August 2011 (Pakistan Independence Day) claimed 11 lives and injured over 100 stunt bikers in 105 reported RTCs in the provincial capital, Lahore [36].

One wheelers are often underage and display dangerous stunts on busy roads, without taking basic precautionary measures such as wearing a helmet, which usually results in severe head and spinal injuries [35-37]. One wheeling is unusual in the developed world and seldom practiced as on busy roads and streets in Pakistan [36]. In Pakistan there are laws banning one wheeling and mandatory helmet wearing for motorcyclists but these have not been strictly enforced [35-37].
The socioeconomic consequences of road traffic injuries include costs of prolonged medical care, loss of the family breadwinner and loss of income due to disability; together these factors often push families into poverty [38].

\section{Conclusion}

The study has described trends of RTCs managed by Rescue 1122 at urban settings in Punjab, Pakistan. The Rescue 1122 ambulance service experienced a higher burden of RTC emergencies in the month of Ramadan 2011 compared with the preceding months of the year. This increase was mostly concentrated among younger ages, especially those driving motorcycles. Furthermore, the majority of RTCs were caused by speeding during the peak rush hours before iftar.

RTCs are a significant public health issue in Pakistan. These crashes and the resultant injuries have considerable physical and socioeconomic impacts; therefore, this issue needs to be addressed. Peer pressure, institutions, stringent law enforcement and personal commitment can play a vital role in improving road safety conditions.

Competing interests: None declared.

\section{References}

1. Global plan for the decade of action for road safety 2011-2012. Geneva, World Health Organization, 2012.

2. Global status report on road safety: time for action. Geneva, World Health Organization, 2009.

3. Waseem $\mathrm{H}$ et al. Epidemiology of major incidents: an EMS study from Pakistan. International Journal of Emergency Medicine, 2011, 4:48.

4. Bhatti JA et al. Differences in police, ambulance and emergency department reporting of traffic injuries on Karachi-Hala road, Pakistan. BMC Research Notes, 2011, 4:75.

5. Ghaffar A, Hyder AA, Masud TI. The burden of road traffic injuries in developing countries: the 1st national injury survey of Pakistan. Public Health, 2004, 118:211-217.

6. Fatmi Z, Hadden WC, Razzak JA. Incidence, patterns and severity of reported unintentional injuries in Pakistan for persons five years and older: results of the National Health Survey of Pakistan 1990-94. BMC Public Health, 2007, 7:152.
7. Ahmed A. Road safety in Pakistan Islamabad. Islamabad, National Road Safety Secretariat, 2007.

8. Raja IA, Vohra AH, Ahmed M. Neurotrauma in Pakistan. World Journal of Surgery, 2001, 25:1230-1237.

9. The characteristics of fatal crashes during the Christmas/New Year holiday period. ATSB Research and Analysis Report, Road Safety. Canberra, Australian Transport Safety Bureau, 2006.

10. Digests of road transport and road accident statistics - 2003. Mauritius, Central Statistics Office, 2004.

11. Cejun L, Chou LC, Dennis U. Trend and pattern analysis of highway crash fatality by month and day. Washington DC, National Center for Statistics and Analysis, 2005.

12. Washington DC, United States Department of Transportation, National Highway Traffic Safety Administration, National Center for Statistics and Analysis, 2002.

13. Cejun Liu, Chou-Lin Chen. Time series analysis and forecast of crash fatalities during six holiday period. Washington DC, 
United States Department of Transportation, National Highway Traffic Safety Administration, 2004.

14. Cejun Liu, Chou-Lin Chen. Forecasts of crash fatalities during summer holiday periods in 2004. Washington DC, United States Department of Transportation, National Highway Traffic Safety Administration, 2004.

15. Ramadan advisory. Karachi, Jinnah Postgraduate Medical Centre, Road Traffic Injury Research \& Prevention Centre, 2010.

16. Road accidents in Bahrain "on the rise" (http://www.tradearabia.com/news/MTR_184998.html, accessed 25 November 2011).

17. Dajani H. Ramadan shifts put extra strain on roads (http:// www.thenational.ae/news/uae-news/ramadan-shifts-putextra-strain-on-roads, accessed 25 November 2011).

18. Shanks NJ, Ansari M, Al-Kalai D. Road traffic accidents in Saudi Arabia. Public Health, 1994, 108:27-34.

19. BBC. Ramadan (http://www.bbc.co.uk/schools/religion/ islam/ramadan.shtml, accessed 26 November 2011).

20. Waseem H, Naseer R, Razzak JA. Establishing a successful prehospital emergency service in a developing country: experience from Rescue 1122 service in Pakistan. Emergency Medicine Journal, 2010, 28:513-515.

21. Tahir N et al. Road traffic crashes managed by Rescue 1122 in Lahore, Pakistan. International Journal of Injury Control and Safety Promotion, 2012, 19:347-350.

22. Masud U, Shehzad MA, Saeed A. Epidemiology of fatalities in road traffic accidents in Faisalabad during 2008-2009 - an autopsy study. APMC, 2011, 5:1-4.

23. Babar M, Muhammad HK, Mohammad WK. Frequency of helmet use among motorcycle riders in Rawalpindi. Professional Medical Journal, 2007, 14:663-668.

24. Sreedharan J, Muttappillymyalil J, Divakaran B. Determinants of safety helmet use among motorcyclists in Kerala. Journal of Injury and Violence Research, 2010, 2:49-54.

25. Gururaj G. Road traffic deaths, injuries and disabilities in India: current scenario. National Medical Journal of India, 2008 21:14-20.
26. Singh YN, Bairagi KK, Das KC. An epidemiological study of road traffic accident victims in medicolegal autopsies. Journal of Indian Academy of Forensic Medicine, 2005, 27:166-169.

27. Pathak A, Desania NL, Verma R. Profile of road traffic accidents and head injury in Jaipur (Rajasthan). Journal of Indian Academy of Forensic Medicine, 2008, 30:6-9.

28. Hyder AA, H Waters, T Phillips. Exploring the economics of motorcycle helmet laws - implications for low and middle-income countries. Asia-Pacific Journal of Public Health, 2007, 19:16.

29. Akbari ME, Naghavi M, Soori H. Epidemiology of deaths from injuries in the Islamic Republic of Iran. Eastern Mediterranean Health Journal, 2006, 12:382-390.

30. Ibrahim MKA, Sukardi A. Use of instrumented motorcycle to study riding behaviors of Malaysian novice motorcyclists. European Journal of Scientific Research, 2011, 49:625-633.

31. Chang HL, Yeh TH. Motorcyclist accident involvement by age, gender, and risky behaviors in Taipei, Taiwan. Transportation Research, 2007, 10:109-122.

32. Savolainen P, Mannering F. Probabilistic models of motorcyclists' injury severities in single and multi-vehicle crashes. Accident Analysis and Prevention, 2007, 39:955-963.

33. Yau K. Risk factors affecting the severity of single vehicle traffic accidents in Hong Kong. Accident Analysis and Prevention, 2003, 36:333-340.

34. Zambon F, Hasselberg M. Factors affecting the severity of injuries among young motorcyclists - a Swedish nationwide cohort study. Traffic Injury Prevention, 2006, 7:143-149.

35. Rescue 1122 (http://www.rescue.gov.pk, accessed 7 October 2011).

36. One-wheeling: passport to death (http://blogs.tribune.com $\mathrm{pk} /$ story/658/one-wheeling-passport-to-death, accessed 3 December 2011).

37. The nation (http://www.nation.com.pk/pakistan-news-newspaper-daily-english-online/lahore/15-Aug-2011/Onewheeling-leaves-11-dead, accessed 18 August 2011).

38. Khan $\mathrm{MH}$ et al. Road traffic accidents; study of risk factors. Professional Medical Journal, 2007, 14:323-327. 